\title{
Analysis on the Innovative Application of Visual Symbol Mud Cuckoo in Package Design
}

\author{
Xiaofei Zhang \\ Huanghe Science and Technology College \\ Zhengzhou, China 450063
}

\begin{abstract}
The research on innovative application of visual symbol Mud Cuckoo in package design, the analysis on its art characters and the discussion on its innovation way and value orientation when applying in package design showed that the visual symbol Mud Cuckoo pushed the new development of package design. It brought a new thought for visual demonstration in package design and provided a new design factor and creative expression for the combination of regional cultural and artistic characters and package design concept.
\end{abstract}

Keywords-Mud Cuckoo; visual symbol; regional characters; package design; innovative application

\section{INTRODUCTION}

With the development of modern arts, more and more people are keen on the traditional folk art design, so the importance of traditional arts is increasingly distinct. Under the promise of traditionalization and the orientation of art, a great many design elites produced a bulk of package designs with typical national characteristics, which generates huge artistic influence. Therefore, valuing and using folk arts appropriately is not just necessary for maintaining and inheriting the traditional artistic culture, but also the only way to innovate art style and form artistic design with typical characteristics. As a typical representative of folk arts, the visual symbol Mud Cuckoo has an excellent traditional designing culture, and it is also a key component of traditional Chinese folk arts, playing an important role in the fields of package design. With the development of economic globalization and the popularization of western design, people gradually realized the significance of traditional artistic culture in package design. So researching innovative methods of the visual symbol Mud Cuckoo and package design produces a significant practical role for the artistic development of package design.

Fund projects: Soft science projects of Henan Science and Technology Department named "A research for the industrialization development of traditional technology of Henan province under the background of constructing Central Plains Economic Zone" (Project NO. 152400410272) Funded project for young backbone teachers in Higher Education of Henan province named "A research for inheritance development of nonmaterial cultural heritage of Henan Folk Art" (Project NO. 2011GGJS-221).

\section{ARTISTIC CHARACTERS OF VISUAL SYMBOL MUD CUCKOO}

\section{A. Exaggeration of the Type}

Formed in the combination of certain society and culture artistic consciousness, the visual symbol Mud Cuckoo's shape has distinct art features and various characters. It truly reflects people's yearning and bailment for living faith and beautiful life, demonstrates folk arts' unique charm in people's life and productivity, and condenses folk arts inheritors' particular artistic conception and shape consciousness.

Visual symbol Mud Cuckoos' shape is simple and vivid. Free and exaggerated structural proportion as well as no punctilious shape form of Mud Cuckoo shows artistic charm with great connotation all the time. The visual shapes of crumby structure, without any decoration, exert an intact outline modeling. Among which the pigeon and turtledove are the most outstanding. Exaggerated plump belly modeling and dynamic and artistic shape of head and tail show exclusive visual art features of Mud Cuckoo. Some wings to fly, some rises to tweet, all of them fully show their lovely and innocent shape and modeling. The Mud Cuckoo saddleman with highlighting head features, uses its straight body replace other details; lean back forward human shape manifests its generous and powerful spirits. The integrated overall shape entirely shows the rural life style in central plain. ${ }^{[1]}$ The shape of mud horse, which is exactly exaggerated, demonstrates its magnificent and strong visual characters by big and forceful neck together with stumpy rounded limbs and tail, the limbs look very steady and integrated because their decorative sense. The visual characteristics of whole shape express plain appearance and unique aesthetic arts.

The shape art of visual symbol Mud Cuckoo is also stylized. Different from bulk of production and modeling manufacture of other folk arts, it is casually made by folk artisan under the ground of understanding and recognition to Mud Cuckoo visual arts and cultural connotation. It is the art inheritance of rare folk art experts teaching by personal example as well as verbal instruction. As one of the best form of folk art, the visual symbol Mud Cuckoo has a very long history and rich cultural heritage origins. Special traditional clay and relatively closed cottage model as well as 
unique form of succession of the production process itself, lay the visual symbol Mud Cuckoo typical stylized characteristics. However, with the calculation of produce experience of generations of folk artisans, they also formed a special artistic skill for charming traditional clay and pass it from generation to generation in formulas art form, making Mud Cuckoo a good continuity and heritage. Such as "small pig looks stubborn, big belly long mouth and ear is broaden". When making the pig, they particularly highlight pig's exaggerated mouth and extremely big ear. With the two characteristics, the pig must be cute. "To shape a beautiful horse, make head higher and belly less", "high head makes horse invigorative, making body should be careful", "Mud Cuckoo, Mud Cuckoo, big head and short tail", "to be fat, all with black", "white line in the black, looks more and more clean-cut" and so on. These skill formulas with visual characters show Mud Cuckoo itself vigorous life and art value as one excellent folk art. ${ }^{[2]}$ Meanwhile, it regulates and restrains folk traditional clay's artistic characters, strengthens exaggeration of the visual art Mud Cuckoo. Wang Lantian, a folk artisan, values exaggeration particularly when making small animals like mud horse, mud lion, mud tiger, mud kylin and so on. The shapes he made, some necks are prolonged causally, gives people a sense of vigor and steady; some delete original factors of body and leg, uses brief and exaggerated shapes, making them smart and delicate. In turn, this greatly intensifies shape features and riches visual art demonstration of Mud Cuckoo.

\section{B. Decoration of Pictures}

The decorative pictures of visual symbol Mud Cuckoo, has an intense features of folk decoration. Besides the simplification of animal's head and people's face, the others mainly use various flowers and plants. Understanding to the spirits of natural vegetation and pursue to beautiful life can be showed with the help of natural and graceful plant pictures. At the same time, applies decorative patterns in accordance with traditionally combined pattern, which centered on lines of peacock tails, bird feathers, boneset, peach and lotus. The main pictures are showed by bloomy flowers, decorated with small dots such as leaves and variously changed lines. So the combination of dots and lines foils decorative style of whole picture. ${ }^{[3]}$ While the demonstration of visual symbol Mud Cuckoo, is mainly by bulk of blank yet the transition of key shape is demonstrated by fully decorated pictures. Different dots and various lines row in order or form certain patterns respectively. These basic combined patterns are mainly from long term life experience and happy life memory of folk artisans, which manifests labor's love to propitious life and hospitality to traditional handicraft and well showed form diversity and art flexibility of Mud Cuckoo visual shapes. At the mean time, the pattern of visual symbol Mud Cuckoo is not welldesigned, it is straight and direct expression of folk artisans' recognition to arts. The generous patterns are both abstract and natural and unrestrained. All dots and lines are completely and directly made, expressing deep cultural deposits in the simplest ways.

\section{Brightness of Colors}

The artistic manifest of visual symbol Mud Cuckoo cannot be separated with bright colors. Typical folk colors function as both color and shape in the expression of visual symbol Mud Cuckoo. The main base color is black, using bright colors with high lightness and purity to paint pictures, direct and beautiful, colorful and pure. Traditional visual symbol Mud Cuckoo adopts China ancient five-color value, that is: black is dark color, white is lightful color, red and green(blue) are bright colors. Extensive black setting off bright colors is a typical feature of Mud Cuckoo, which manifests the unique black culture. However, black has the specific Chinese cultural connotation and a long history since ancient times. One article named Wenyan in the Book of Changes recorded that the heaven is dark (black) and the earth is yellow. Dark means black. The emperor Zhuanxu worship dark during his lifetime, so he named the palace where he live xuan palace (dark palace) and named himself xuan emperor. Dark also means tolerance and acceptance, which is also unfathomable. Ancient ancestors regarded black as righteous and natural color, because black in Tai Chi is the symbol of essence and matrix. Gangjianyizhilu (an ancient book) recorded that the Xia dynasty takes black as title of honor and takes the black bird as totem. Black color is representative of righteous artistic character, which is also demonstrated in modern times. ${ }^{[4]}$ The colors of visual symbol Mud Cuckoo are clearly contrasted. The black with profound meanings carries many bright colors with high lightness and purity, which produces a strongly contrasted visual effect, brilliant and outstanding, fully demonstrates animate and flexible traditional arts. The color application of visual symbol Mud Cuckoo is not based on scientific color theory system, but mainly on the basic of folk artisans' life experience and plain aesthetic psychology. Even though this violates modern color aesthetic principles, it shows particular and pure color theory relationship. It is exactly the application of this strongly contrasted color relationship that produces particular folk arts, showing the folk art's character-- Big vulgar namely jedaiah. ${ }^{[5]}$ Meanwhile, folk artisans use colors emotionally with the apperception of beautiful life on different view, and their optimistic and active attitude and pursue to beautiful life demonstrate intense visual impact and deep cultural connotation of Mud Cuckoo to a full extent.

\section{INNOVATIVE METHODS OF VISUAL SYMBOL MUD Cuckoo in PACKAge Design}

\section{A. Finding Intersection of Design Connotation and Visual Symbol In Mud Cuckoo}

Visual symbol Mud Cuckoo is direct art feelings of people to life. Based on folk artists perceive life experiences and expectations of psychological longing for a better life, it is not standard and orderly innovative design. Thing features of Packaging design determine the combination of packaging design objects and visual symbol Mud Cuckoo, so people have to deeply analysis and rationally generalize the visual symbol Mud Cuckoo and the cultural need of package design objects. The character grasp targeted package design should 
be based on certain traditional implied meaning and particular cultural connotation, so its new design conception becomes more important in package design activities.

Because of various shapes and exaggerated features of visual symbol Mud Cuckoo, and because different visual symbols mean different culture, ${ }^{[6]}$ the designer must be guided by cultural background and seek the intersection of visual symbol Mud Cuckoo and package design objects when apply it innovatively, and make the beauty of tradition and design fused mutually. For instance, the color used in some gift package, people use Mud Cuckoo's color system directly. Decorating bright colors by black, both highlight the whole and deep cultural connotation.

\section{B. Innovative Application of form Language of Visual Symbol Mud Cuckoo in Package Design}

As to specific package design, because of different design orientation and design target of package design objects, the innovative application of visual symbol Mud Cuckoo should value different design and artistic pursue. Based on grasping the whole package design objects, researching the artistic expression matched visual symbol Mud Cuckoo according to the related design need. All in all, as a traditional art form, the visual symbol Mud Cuckoo serves people originally, for people's appreciation and entertainment. To display visual symbol's charm in a suitable way in new package design field not only require designers pay attention to the innovation of visual symbol Mud Cuckoo, but also take the value orientation and moral orientation into consideration, such as function, the audience, regional cultural characters and beauty-appreciation of package design objects. ${ }^{[7]}$ Visual symbols in any form pursue beautiful visual entertainment and deep designing emotions. Seeing from the features of visual symbol Mud Cuckoo, it values shape and decoration matched harmoniously, which has deep design connotation and unique visual principles. Therefore, the combination of package and visual symbol should be completed under the ground of following the basic designing language of Mud Cuckoo.

\section{Individualization Language Expression of Visual Symbol Mud Cuckoo in the Multiculture Situation}

In the trend of national design development, the importance of national traditional culture becomes more and more distinct individualized and innovative design becomes the main fashion of the package design trend. Based on showing fundamental functions, the more important things is how to display itself unique traditional culture connotation and excellent national culture and inner spirit in the world.

\section{VAlUE ORIENTATION OF VisUal SymbOL MUd CUCKOO IN PACKAGE DESIGN}

With the progress of society and the development of modern arts, people's subjective consciousness and artistic conception are changed and improved along with them. The traditional cultural art form visual symbol Mud Cuckoo both can rich visual language of package design and broaden its artistic innovation and shapes under the specific influence and endurance. ${ }^{[8]}$ The development of anything can be made without constant update and creation. The visual symbol Mud Cuckoo, as one particular traditional art, must be inherited and passed to descendents in better art form. Designers should be familiar with artistic features and cultural connotations of traditional arts, continually dig out the inner cultural connotations, and make the best use of their merits to innovate the arts. Based on functionality and conveying features of product in packaging design, continuously improve and develop visual symbol Mud Cuckoo's innovative use of the national traditional arts. Designers should apply visual symbol Mud Cuckoo with Chinese cultural characters according the features of package design objects, making the package design both displaying national culture and widely accepted by people.

Whether the creation subjects or the shape pictures of visual symbol Mud Cuckoo is the direct expression of deep emotion in folk artisans' heart, they have their own artistic consciousness, which bring people great emotion enjoyment. Facing a great many reference materials for package design, their individual visual character and originality becomes increasingly weak. The package they designed is lack of personality under the same quality, lost their emotional appeal and design soul. The really good design should be the works of designers created under the ground of deep understanding and cognition to the products and its culture as well as the combination of culture and art connotations. While visual symbol Mud Cuckoo is restrained by nothing, directly express the emotions in life and heart. It is an inner spiritual expression returned to its nature, well showed emotions in design.

\section{CONCLUSION}

Visual symbol Mud Cuckoo is an expression of traditional national arts, is an important source for design development. With the continuous development of contemporary design arts, the visual symbol Mud Cuckoo, with its particular art form, causally shape, brief decorative arts and exaggerated and direct colors, is fond of by people, shows its unique cultural connotation in package design. This specific traditional art form has a strong visual language, provides profound creative consciousness for development of new packages design, caters development of modern times well and becomes an indispensable visual language for the improvement of package design.

\section{REFERENCES}

[1] Li Xiaorui. The artistic features and inheritance of mud toys in northern Henan-take the case study of Mud Cuckoo in Jun county. Master's degree thesis of Fujian Normal University.

[2] Wang Wenjie. Creative arts and form beauty of folk arts as well as its modern beauty-appreciation. Master's degree thesis of Hebei Universiy, 2004

[3] Wang Shucun. China folk art shapes [M].Hunan Fine art Press, 2006

[4] Liu Hongwei. Understanding for extension of folk pictures color in package design. [J]. package engineering, 2012, (4): page 133

[5] Wang Yajing, Cao Guohua. Folk arts color of central plain and originality of modern package design. [J]. package engineering, 2010, 31 (10) : page 47-50 
[6] Jin Ke. Traditional folk arts and package design.[J]. package engineering, August, 2007.

[7] Li Jie. New the soul of modern package design.[J].package engineering, April. 2007

[8] Liu Lin. National package design [M]. Hubei Fine Arts Press, 2004. 